\title{
Relative Ion Permeability of Normal and Cystic Fibrosis Nasal Epithelium
}

\author{
Michael Knowles, John Gatzy, and Richard Boucher, Departments of \\ Medicine and Pharmacology, School of Medicine, University of North \\ Carolina, Chapel Hill, North Carolina 27514
}

\begin{abstract}
A B S TRACT The raised transepithelial electric potential difference (PD) across respiratory epithelia in cystic fibrosis (CF) has suggested an abnormality in ion permeation. We characterized this abnormality further by measuring in the nasal epithelia of CF and normal subjects the concentration-PD relationship for amiloride, an inhibitor of cell $\mathrm{Na}^{+}$permeability, and $\mathrm{PD}$ responses to superfusion with solutions of different composition. Amiloride was more efficacious in the CF subjects but the $\mathrm{ED}_{50}$ was not different from that of normals $\left(\sim 2 \times 10^{-6} \mathrm{M}\right) . \mathrm{Na}^{+}$replacement by choline induced effects similar to those of amiloride, i.e. a greater depolarization in CF subjects. A 10-fold increase in the $\mathrm{K}^{+}$concentration of the perfusate induced a small $(<10 \mathrm{mV})$ depolarization in both subject populations. When $\mathrm{Cl}^{-}$in the perfusate was replaced by gluconate or $\mathrm{SO}_{4}^{2-}$ the nasal PD of normal subjects hyperpolarized (lumen became more negative) by $\sim 35$ $\mathrm{mV}$. A significantly smaller response $(<17 \mathrm{mV})$ was induced in CF homozygotes but not in heterozygotes $(38 \mathrm{mV})$. The smaller response of CF subjects appears to reflect an absolute decrease in luminal surface $\mathrm{Cl}^{-}$ permeability because pretreatment with amiloride did not increase the response to $\mathrm{Cl}^{-}$free solution $(7 \mathrm{mV})$. Accordingly, three abnormalities (decreased $\mathrm{Cl}^{-}$permeability, raised PD, greater amiloride efficacy) have been identified in $\mathrm{CF}$ respiratory epithelia. Whereas "excessive" active $\mathrm{Na}^{+}$transport can account for these abnormalities and the dessication of airway surface liquid, it is possible that a lower lumenal cell membrane $\mathrm{Cl}^{-}$permeability and inhibition of a potential path of $\mathrm{Cl}^{-}$secretion can also explain the observations.
\end{abstract}

\section{INTRODUCTION}

Cystic fibrosis $(\mathrm{CF})^{1}$ is characterized by abnormal fluid and solute balance across the epithelia of several organs

\footnotetext{
Address correspondence to Dr. Knowles.

Received for publication 7 September 1982 and in revised form 20 December 1982.

${ }^{1}$ Abbreviations used in this paper: CF, cystic fibrosis; KBR, Krebs bicarbonate Ringer's solution.
}

$(1,2)$. The lung is usually the critical organ because thickened airway liquid appears to contribute to recurrent infection with progressive loss of ventilatory function (3). We established that transepithelial electric potential differences (PD) across the nasal mucosa and bronchi of patients with cystic fibrosis were at least twice voltages from the same regions of normal subjects, heterozygote subjects, or patients with diseases that share some of the sequellae of cystic fibrosis (4). The PD of both normal and CF subjects were inhibited by superfusion of amiloride onto the luminal surface but the drug induced a greater change in CF patients. The specificity of amiloride's action on other epithelia suggested that the PD across upper airway epithelia of normal and CF subjects was linked to the translocation of $\mathrm{Na}^{+}$.

In this paper we attempt to more completely characterize the paths of ion permeation across the nasal epithelium of CF and normal subjects from measurements of $(a)$ the concentration-voltage relationship for amiloride perfusion onto the nasal mucosa and $(b)$ biionic and dilution PDs generated by superfusion of the luminal surface of the nasal mucosa with solutions of different ionic composition.

\section{METHODS}

Subjects. (a) CF patients. The diagnosis of CF was established by both clinical criteria and raised sweat electrolytes in 8 males and 12 females (mean age $=22.0[ \pm 1.1]$ yr). Because of the long duration of superfusion with solutions of different ion composition (see below), the 14 subjects who participated in these studies were at least $16 \mathrm{yr}$ old. (b) Normal. Age and sex matched subjects (20 males, 23 females, mean age $=21.1[ \pm 1.2] \mathrm{yr}$ ) without history of respiratory or other disease, medication use, or cigarette smoking, served as controls. (c) Heterozygotes. Four CF mothers, mean age $29( \pm 4)$ yr, were studied

Drugs and solutions. Mammalian Krebs bicarbonate Ringer's solution (KBR) was the standard superfusion (5). The $\mathrm{Na}^{+}$concentration of the solution was reduced by replacing $\mathrm{NaCl}$ with choline $\mathrm{Cl}$ and choline bicarbonate (Sigma Chemical Co., St. Louis, MO). The $\mathrm{K}^{+}$concentration was raised by replacing $\mathrm{NaCl}$ with $\mathrm{KCl}$. The $\mathrm{Cl}^{-}$concentration was reduced by replacing $\mathrm{NaCl}$ with $\mathrm{Na}$ gluconate (Sigma 
Chemical Co.), or in a few experiments, $\mathrm{Na}_{2} \mathrm{SO}_{4}$ that was made isosmotic with mannitol. The $\mathrm{NaCl}$ of solutions that were nominally free of both ions was replaced by choline gluconate, which was prepared by titration of gluconic acid with choline bicarbonate. Osmolality and the $\mathrm{Na}^{+}, \mathrm{K}^{+}$, and $\mathrm{Cl}^{-}$concentrations were within $7 \%$ of expected values. All solutions were gassed with $95 \% \mathrm{O}_{2}-5 \% \mathrm{CO}_{2}$ and had $\mathrm{pH}$ of 7.3-7.4. Amiloride $\mathrm{HCl}$, a gift of Merck Sharp and Dohme Div. Merck, Inc., Rahway, NJ, was dissolved in the appropriate Ringer's solution.

Superfusion of the nasal surface. Responses of the nasal transepithelial PD to superfusion with different solutions were measured by a technique adapted from previous studies (6). Briefly, a Ringer-agar reference bridge connected to a calomel electrode was inserted subcutaneously. A double-lumen catheter was positioned at a site under the inferior turbinate, $1-3 \mathrm{~cm}$ from the anterior tip. Sites were chosen such that slight movement did not change the PD. In general, the PDs were typical of those reported for the inferior surface (6). Ringer's solution that was connected by a Ringer-agar bridge to a calomel electrode, was perfused slowly $(0.2 \mathrm{ml} /$ min) through one lumen. The second tube was attached to a glass coil in a $37^{\circ} \mathrm{C}$ water-bath that was connected to a separate perfusion pump. After the base-line measurement (PD did not change by $>6 \%$ during $1 \mathrm{~min}$ ), perfusion through the first pump was stopped and solution flow through the second catheter was begun. For amiloride dose-effect studies, the second perfusion rate was $0.4 \mathrm{ml} / \mathrm{min}$ for $3 \mathrm{~min}$. Solutions of different composition were superfused for $5 \mathrm{~min}$ at $4 \mathrm{ml} /$ min and then for $30 \mathrm{~s}$ at $15 \mathrm{ml} / \mathrm{min}$. At the end of each superfusion sequence, the nasal surface was superfused again with Ringer's solution for $3 \mathrm{~min}$. Subjects were exposed to a superfusion sequence (usually one or two modified solutions, see Tables I and II) no more frequently than once a week. PDs between the exploring and subcutaneous bridges were measured with a high impedence voltmeter and were corrected for the appropriate liquid junction potential by the method described previously (7).

Statistics. Mean changes in nasal voltage induced by amiloride or by modification of superfusion solution composition in a group of subjects were evaluated by paired $t$ test. Differences between subject groups in base-line PD or the magnitude of response to a maneuver were assessed by the $t$ test for independent means. $P<0.05$ was considered to be significant. Means $( \pm \mathrm{SE})$ are reported.

\section{RESULTS}

The dose-effect relationship for nasal mucosa superfused with Ringer's solution in vivo with amiloride is shown in Fig. 1. The average PD across the untreated epithelium of 34 normal subjects was $29.1( \pm 1.6) \mathrm{mV}$ (lumen negative) whereas the corresponding voltage in $18 \mathrm{CF}$ subjects was $67.7( \pm 1.8) \mathrm{mV}$ (lumen negative). Superfusion with amiloride induced a dose-dependent inhibition of the voltage. Comparable concentrations of amiloride always induced a greater absolute change in the PD of CF subjects. However, when the change in voltage was normalized for the magnitude of the resting PD in each subject, only the maximal effect induced by concentrations of amiloride that exceeded $10^{-5} \mathrm{M}$ was significantly higher in CF subjects. The doses required to reduce the $\mathrm{PD}$ of normal and $\mathrm{CF}$ subjects by $50 \%\left(\mathrm{ED}_{50}\right)$ were $2 \times 10^{-6}$ and 3

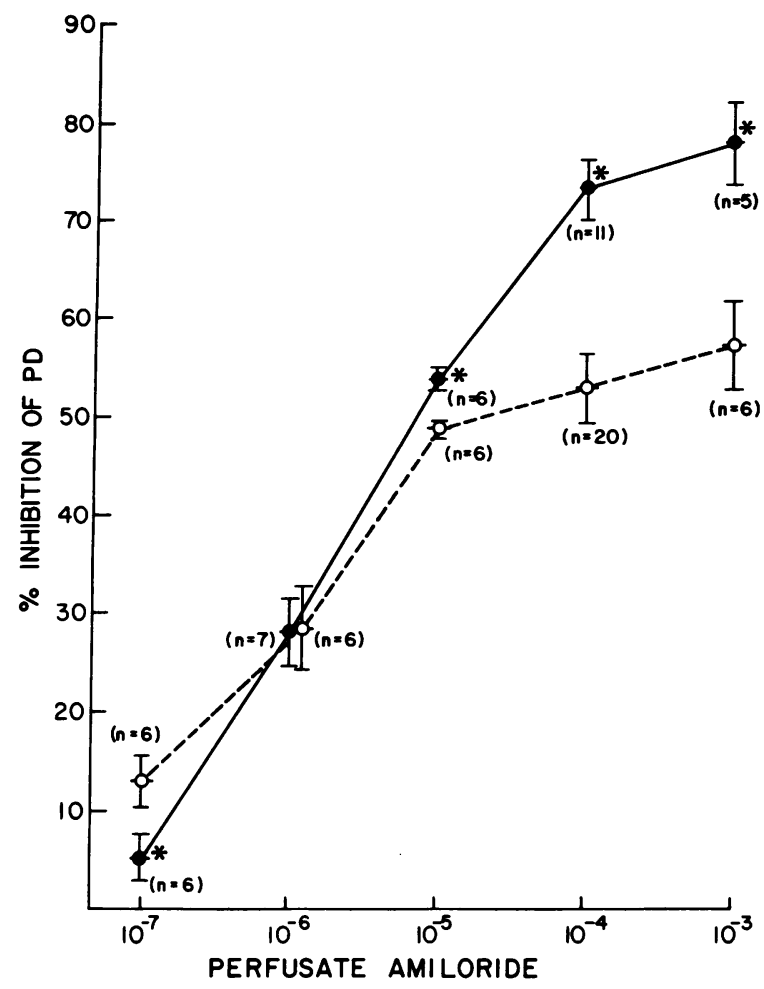

Figure 1 Dose-effect relationship for inhibition of nasal PD by amiloride (moles per liter). The change in PD induced by each concentration of amiloride was divided by the PD recorded in each subject during superfusion with drug-free Ringer's solution and the quotient was multiplied by 100 . Open circles and the dashed line represent results from normal subjects; filled circles and the solid line denote data from subjects with cystic fibrosis. Each point is the mean of observations on the number $(n)$ of subjects noted in parentheses. Vertical bars denote SE.

$\times 10^{-6} \mathrm{M}$, respectively. Slightly greater inhibition $(<10 \%)$ could be induced by greater infusion rates $(4$ $\mathrm{ml} / \mathrm{min}$ ) but the drug always induced, at comparable infusion rates, a greater maximal effect in CF than in normal subjects.

Because the specificity of amiloride's inhibition of $\mathrm{Na}^{+}$entry across the luminal border of epithelial cells implied a contribution of $\mathrm{Na}^{+}$translocation to the PD in nasal epithelia, we also assessed the voltage response to superfusion with $\mathrm{Na}^{+}$-free solutions. Exposure to $\mathrm{Na}^{+}$replete Ringer solution from the second pump did not change PD (Table I). Like exposure to amiloride, $\mathrm{Na}^{+}$-free solution induced large reductions in $\mathrm{PD}$ in both groups and the response in CF subjects was both absolutely and proportionately greater.

The PD change induced by this or any other modification of the superfusion solution was not significantly different at the higher flow rate. This finding indicates that the lower flow resulted in the maximal 
TABLE I

Changes in the Bioelectric PD of the Nasal Mucosa of Normal and CF Subjects Induced by Replacement of Cation in the Perfusion Solution

\begin{tabular}{|c|c|c|c|c|c|c|c|c|}
\hline & \multicolumn{8}{|c|}{ Subjects } \\
\hline & & \multicolumn{3}{|c|}{ Normal } & & \multicolumn{3}{|c|}{ Cystic fibrosis } \\
\hline & & $\begin{array}{l}\text { Base line } \\
\text { (KBR) }\end{array}$ & $\begin{array}{l}\text { Modified } \\
\text { perfusate }\end{array}$ & $\begin{array}{c}\mathrm{PD} \\
\text { change }\end{array}$ & & $\begin{array}{l}\text { Base line } \\
\text { (KBR) }\end{array}$ & $\begin{array}{l}\text { Modified } \\
\text { persuate }\end{array}$ & $\begin{array}{c}\text { PD } \\
\text { change }\end{array}$ \\
\hline & & & $P D(m V)$ & & & & $P D(m V)$ & \\
\hline $\begin{array}{l}\text { Composition and sequence of } \\
\text { superfusion of modified } \\
\text { solution } \ddagger\end{array}$ & $\mathbf{N}$ & & $\begin{array}{l}\text { Mean } \\
(\mathrm{SEM})\end{array}$ & & $\mathbf{N}$ & & $\begin{array}{l}\text { Mean } \\
\text { (SEM) }\end{array}$ & \\
\hline $\mathrm{KBR}$ to $\mathrm{KBR}$ & 7 & $\begin{array}{r}-27.9 \\
(1.3)\end{array}$ & $\begin{array}{r}-29.4 \\
(1.9)\end{array}$ & $\begin{array}{c}-1.5 \\
(0.7)\end{array}$ & 7 & $\begin{aligned}-70.8 \\
(4.7)\end{aligned}$ & $\begin{array}{r}-73.8 \\
(4.5)\end{array}$ & $\begin{array}{c}-3.0 \\
(1.3)\end{array}$ \\
\hline $\mathrm{KBR}$ to choline $\mathrm{Cl}^{-}$ & 7 & $\begin{array}{r}-30.5 \\
(4.2)\end{array}$ & $\begin{array}{r}-7.9 \\
(2.1)\end{array}$ & $\begin{array}{r}+22.6 \S \\
(2.5)\end{array}$ & 8 & $\begin{array}{r}-70.5 \\
(5.4)\end{array}$ & $\begin{array}{r}-13.5 \\
(3.0)\end{array}$ & $\begin{array}{c}+57.0 \S^{\prime \prime} \\
(3.5)\end{array}$ \\
\hline $\begin{array}{l}\mathrm{KBR} \text { to amiloride }\left(10^{-3} \mathrm{M}\right) \\
\text { in } \mathrm{KBR}\end{array}$ & 5 & $\begin{array}{r}-30.8 \\
(2.9)\end{array}$ & $\begin{array}{l}-8.0 \\
(0.4)\end{array}$ & $\begin{array}{r}+22.8 \S \\
(2.5)\end{array}$ & 5 & $\begin{array}{r}-59.2 \\
(3.2)\end{array}$ & $\begin{array}{r}-11.2 \\
(2.0)\end{array}$ & $\begin{array}{c}+48.0 \S^{\prime \prime} \\
(1.9)\end{array}$ \\
\hline $\begin{array}{l}\text { to amiloride }\left(10^{-3} \mathrm{M}\right) \\
\text { in choline } \mathrm{Cl}^{-}\end{array}$ & & & $\begin{array}{c}-1.0 \\
(1.7)\end{array}$ & $\begin{array}{c}+7.0 \pi \\
(1.9)\end{array}$ & & & $\begin{array}{c}-1.3 \\
(3.0)\end{array}$ & $\begin{array}{r}+9.9 \pi \\
(1.4)\end{array}$ \\
\hline $\begin{array}{l}\mathrm{KBR} \text { to } 50 \text { meq } \mathrm{K}+, 90 \mathrm{meq} \\
\mathrm{Na}^{+}\end{array}$ & 6 & $\begin{array}{r}-29.8 \\
(4.6)\end{array}$ & $\begin{array}{r}-21.6 \\
(5.2)\end{array}$ & $\begin{array}{r}+8.2 \S \\
(2.6)\end{array}$ & 6 & $\begin{array}{r}-65.8 \\
(4.7)\end{array}$ & $\begin{array}{r}-57.9 \\
(8.4)\end{array}$ & $\begin{array}{r}+7.9 \\
(3.7)\end{array}$ \\
\hline $\begin{array}{l}\text { KBR to } 50 \text { meq choline, } 90 \\
\text { meq } \mathrm{Na}+\end{array}$ & 5 & $\begin{array}{r}-33.4 \\
(4.7)\end{array}$ & $\begin{array}{r}-29.3 \\
(5.1)\end{array}$ & $\begin{array}{c}+4.1 \\
(1.9)\end{array}$ & 5 & $\begin{array}{r}-71.6 \\
(8.4)\end{array}$ & $\begin{array}{r}-68.3 \\
(8.1)\end{array}$ & $\begin{array}{c}+3.3 \\
(4.1)\end{array}$ \\
\hline
\end{tabular}

- A negative (-) change represents hyperpolarization, i.e., the lumen became more negative; a positive (+) change denotes depolarization. $\downarrow$ Drug and major solute composition, e.g., amiloride $\left(10^{-3} \mathrm{M}\right)$ in $\mathrm{KBR}$ to amiloride in choline $\mathrm{Cl}^{-}=$superf usion with amiloride $\left(10^{-3}\right.$ M) containing solution followed by superfusion with an amiloride containing solution with all $\mathrm{Na}+$ replaced by choline.

$\$$ Change from baseline $(P<0.05)$.

"Different from change induced in normals $(P<0.05)$.

I Change induced from the steady state established by superfusion with the first modified solution $(P<0.05)$.

change in composition in the vicinity of the exploring bridge. In addition, reexposure of the nasal epithelium, after each sequence of ion replacement (without amiloride), to conventional Ringer solution established a steady-state PD that was not significantly different from the initial base line (data not shown).

Since superfusion with $\mathrm{Na}^{+}$-free solution with amiloride after amiloride pretreatment resulted in a $<10$ $\mathrm{mV}$ further decrease in the PD of the nasal epithelia of both groups (Table I), we reasoned that most of the PD change induced by $\mathrm{Na}^{+}$-free Ringer was amiloride sensitive. The amiloride insensitive responses of the two subject populations were not different.

The exaggerated response of $\mathrm{CF}$ airways to amiloride or $\mathrm{Na}^{+}$replacement suggested that the path of $\mathrm{Na}^{+}$ permeation played a disproportionately greater role in the determination of PD in CF epithelium. However, this pattern of response would also be expected if $\mathrm{Na}^{+}$permeation was "normal" and permeability of the barrier to other ions was abnormally low. We eval- uated this alternative by assessing the transepithelial voltage response to changes in the concentration of other major ions in the solution that was superfused onto the surface of the nasal mucosa.

When the $\mathrm{K}^{+}$concentration was raised 10 -fold to 50 $\mathrm{meq} /$ liter, PD across the nasal mucosa of both groups of subjects fell by $\sim 8 \mathrm{mV}$. The change in CF subjects was not significant. Replacement of an equivalent concentration of $\mathrm{Na}^{+}$in the bathing solution by choline did not change the PD in both groups of subjects significantly. Although the response to $\mathrm{K}^{+}$replacement tended to be slightly greater than that to choline, the differences were not significant.

In contrast, replacement of $\mathrm{Cl}^{-}$by gluconate or sulfate resulted in a rise in the PD of normal subjects that was more than twice that of CF subjects (Fig. 2 and Table II). Further, the voltage change induced by superfusion with $\mathrm{Cl}^{-}$-free media did not require $\mathrm{Na}^{+}$in the solution ( $\mathrm{NaCl}$ replaced by choline gluconate). A PD change of $38( \pm 4) \mathrm{mV}$ was induced in four het- 


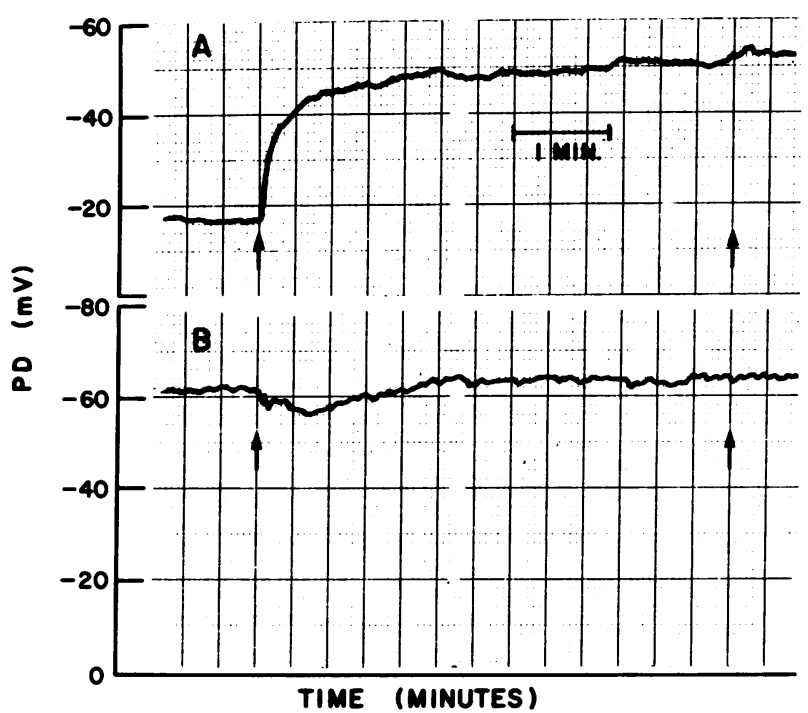

Figure 2 Typical time course of nasal PD of a normal subject (panel A) and a subject with cystic fibrosis (panel B). Arrows on the left denote switch from superfusion $(0.2 \mathrm{ml} /$ min) with conventional Ringer's solution to a solution in which all $\mathrm{Cl}^{-}$was replaced by gluconate $(4 \mathrm{ml} / \mathrm{min})$. Arrows on the right indicate an increase in the rate of superfusion with $\mathrm{Cl}^{-}$free solution to $15 \mathrm{ml} / \mathrm{min}$. PD during superfusion with $\mathrm{Cl}^{-}$free solution is not corrected for the tip potential of the bridge on the nasal surface and is underestimated by $9 \mathrm{mV}$.

erozygotes by superfusion with $\mathrm{Cl}^{-}$-free solution. This response was not different from that of normal subjects.

The relative permeabilities of $\mathrm{Na}^{+}$and $\mathrm{Cl}^{-}$across nasal epithelium can also be assessed from the PD change induced by isosmotic dilution of $\mathrm{NaCl}$ with a nonelectrolyte (sucrose). First, we measured the effect of the change in $\mathrm{Na}^{+}$concentration alone (replacement with choline) and then superfused with diluted Ringer's solution. Small but significant reductions in the PD of both groups accompanied exposure to $60 \mathrm{meq} / \mathrm{liter}$ $\mathrm{Na}^{+}$. The response of CF subjects was greater. Subsequent ion dilution and choline removal resulted in a substantial increase in the PD of normals and an insignificant change in $\mathrm{CF}$ subjects.

The blunted response of $\mathrm{CF}$ nasal epithelia to $\mathrm{Cl}^{-}$free solution could reflect lower relative or absolute $\mathrm{Cl}^{-}$permeability. We tried to distinguish between these alternatives by inhibiting $\mathrm{Na}^{+}$permeability with amiloride and then measuring the response to a $\mathrm{Cl}^{-}$free solution with amiloride. Pretreatment with amiloride induced the characteristic fall in PD. Subsequent perfusion with amiloride in $\mathrm{Cl}^{-}$-free solution induced an increase in PD of normal subjects that was similar to voltage change induced by $\mathrm{Cl}^{-}$-free solution without drug. The voltage response in CF subjects was again smaller than that of normals. Compared with
CF subjects that were not pretreated with amiloride, the response of $\mathrm{CF}$ subjects to $\mathrm{Cl}^{-}$-free solution with amiloride was smaller.

\section{DISCUSSION}

Transepithelial electric PDs under the inferior turbinate were twofold greater in $\mathrm{CF}$ than in normal subjects (Tables I and II). These results are comparable to our earlier measurements of a larger CF population (4).

The dose-effect study with amiloride (Fig. 1) demonstrated that the drug induced a greater ceiling effect on the nasal PD of CF subjects. Both absolute voltage changes and the changes normalized for base-line PD that were induced by maximal concentrations of amiloride were always greater in CF than in normal subjects (Fig. 1 and Table I). However, $\mathbf{E D}_{50}$ of normal subjects and subjects with cystic fibrosis were similar $\left(2\right.$ or $\left.3 \times 10^{-6} \mathrm{M}\right)$. These values fall into the range reported for respiratory epithelia excised from adult human subjects (8) and for the other $\mathrm{Na}^{+}$absorbing epithelia (9). In addition, similar dose-effect relationships for PD or short circuit current have been obtained in vitro from nasal and bronchial epithelia excised from $\mathrm{CF}$ and normal subjects. ${ }^{2}$

Amiloride's primary action on CF and normal nasal mucosa is probably restricted to cellular paths of $\mathrm{Na}^{+}$ translocation. An in vitro study of nasal epithelia excised from a limited number of normal and CF subjects demonstrated that $\mathrm{Na}^{+}$absorption was the only measurable active ion transport across these tissues under resting conditions. ${ }^{2}$ Moreover, basal $\mathrm{Na}^{+}$transport equalled the short circuit current and was blocked by amiloride. It is more difficult to test amiloride specificity in vivo. The similarity between PD changes induced by amiloride and by $\mathrm{Na}^{+}$-free solution could result from a common mechanism. However, drug-induced and $\mathrm{Na}^{+}$-free voltage responses of the nasal mucosa would not be expected to be identical. For example, whereas both maneuvers limit the access of $\mathrm{Na}^{+}$to the transport system, only replacement of $\mathrm{Na}^{+}$ in the superfusion is likely to reverse the $\mathrm{Na}^{+}$gradient across the luminal (apical) membranes of the epithelial cells and should not affect $\mathrm{Na}^{+}$permeability. In spite of these differences, replacement of $\mathrm{Na}^{+}$, like exposure to amiloride, induced a greater change in PD in CF than in normal subjects. Because replacement of $\mathrm{Na}^{+}$ in a Ringer solution that contained a maximal concen-

${ }^{2}$ Knowles, M. R., M. J. Stutts, A. Spock, N. Fischer, J. T. Gatzy, and R. C. Boucher. Abnormal ion permeation through cystic fibrosis respiratory epithelium. Science (Wash. DC). In press.

Knowles, M. R., A. Spock, J. T. Gatzy, and R. C. Boucher. 1982. Amiloride sensitivity and ion permeabilities of $C F$ and normal human bronchi. Clin. Res. 30: 861a. (Abstr.) 
TABLE II

Changes in the Bioelectric PD of the Nasal Mucosa of Normal and CF Subjects Induced by Replacement of Anion, Cation and Anion, and by Ion Dilution of the Perfusion Solution

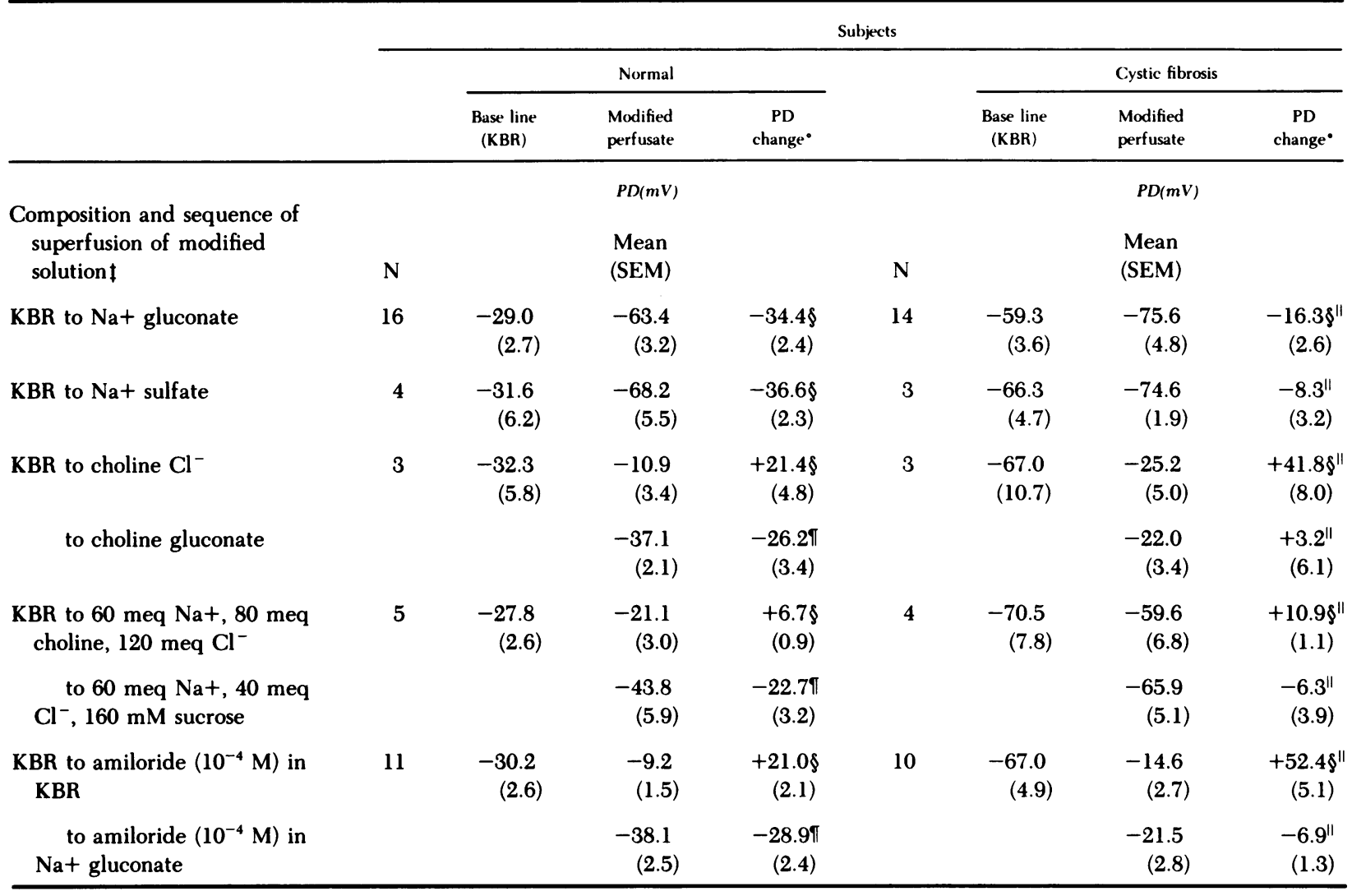

- A negative (-) change represents hyperpolarization, i.e., the lumen became more negative; a positive (+) change denotes depolarization. ‡ Drug and major solute composition, e.g., choline $\mathrm{Cl}^{-}$to choline gluconate $=$superfusion with a solution with all $\mathrm{Na}+$ replaced by choline followed by superfusion with solution with all $\mathrm{NaCl}$ replaced by choline gluconate.

$\$$ Change from base line $(P<0.05)$.

"Different from change induced in normals $(P<0.05)$.

ף Change induced from the steady-state established by superfusion with the first modified solution $(P<0.05)$.

tration of amiloride induced an additional depolarization that was similar in CF and normal subjects, we conclude that most of the voltage response to $\mathrm{Na}^{+}$-free solution alone was the consequence of $\mathrm{Na}^{+}$permeation through amiloride-sensitive paths and that amilorideinsensitive $\mathrm{Na}^{+}$paths make a similar contribution to the responses of both populations of subjects. In addition, preliminary data suggest that the small $(<20 \%$ or $1 \mathrm{~ms} / \mathrm{cm}^{2}$ ) reduction in conductance of excised airway epithelia (nasal turbinate and polyp, bronchi) induced by amiloride is not greater in tissue from CF subjects. ${ }^{2}$ These results imply that amiloride-sensitive ion fluxes across CF airway epithelia do not, compared to paths across normal tissue, contribute disproportionately to conductance.

The voltage change induced by one other modification of Ringer's solution was not "abnormal" in CF subjects. A 10 -fold increase in the $\mathrm{K}^{+}$concentration of the superfusion solution resulted in a small depolarization that was not significantly different in either population from the response induced by replacement of an equivalent amount of solution $\mathrm{Na}^{+}$by choline. These results suggest that the epithelial surface is not $\mathrm{K}^{+}$permselective. Our experience with other airway epithelia has shown that equivalent radii of paths around the surface cells are large $(>4 \mathrm{~nm})$ and would not be expected to restrict small ion movement (10, 11). The similar voltage responses of $\mathrm{CF}$ and normal subjects to the high $\mathrm{K}^{+}$solution imply that the $\mathrm{K}^{+}$permeabilities of the luminal cell membrane and the paracellular path are comparable in both populations of subjects.

In contrast, replacement of $\mathrm{Cl}^{-}$in the superfusion solution with or without $\mathrm{Na}^{+}$induced a greater hy- 
perpolarization of the nasal PD of normal than $\mathrm{CF}$ subjects. If $\mathrm{Cl}^{-}$and gluconate diffusion in the paracellular shunt follow the expectations for diffusion in free solution, this path can contribute no more than $9 \mathrm{mV}$ to the hyperpolarization (i.e., equal and opposite to the liquid junction PD at the bridge). Consequently, the response in normal subjects probably reflects $\mathrm{Cl}^{-}$ permselectivity of the apical surface. This conclusion is supported by the hyperpolarization induced by dilution of the $\mathrm{NaCl}$ in the superfusion solution with isosmotic sucrose (Table II). It is likely that the $\mathrm{Cl}^{-}$ permeability of the luminal surface of the epithelium of CF subjects is substantially smaller. Not only was the $\mathrm{PD}$ response to $\mathrm{Cl}^{-}$replacement smaller than the response of normals, but $\mathrm{Cl}^{-}$replacement coupled with a maximal concentration of amiloride, a maneuver that would be expected to minimize the contribution of $\mathrm{Na}^{+}$diffusion to the $\mathrm{PD}$, decreased rather than increased the hyperpolarization. Accordingly, both the relative and absolute $\mathrm{Cl}^{-}$permeability of the apical surface of CF epithelium appear to be smaller than those of normal subjects. These differences probably cannot be accounted for by differences between the ion composition of normal and CF epithelium because the change in PD across the barrier should be independent of cell and interstitial ion concentrations so long as these concentrations do not change during the period of measurement (12).

Our studies of bioelectric properties and ion flow across airway epithelia have revealed three major differences between normal and CF tissue. CF epithelia are characterized by $(a)$ a greater transepithelial PD, (b) a greater maximal response to amiloride, and (c) a smaller $\mathrm{Cl}^{-}$permselectivity of the luminal surface.

Several defects or a single defect could account for these observations. We originally proposed on the basis of increased amiloride efficacy that the raised PD or airway epithelia was the consequence of an "excessive $\mathrm{Na}^{+}$absorption" (4). This hypothesis is neither supported nor discounted by the present study or by our limited observations from airway epithelia excised from normal and CF subjects. ${ }^{2}$ We considered earlier the possibility that a defect in the $\mathrm{Na}^{+}$transport could result from a change in paracellular $\mathrm{Na}^{+}$conductance, $\mathrm{Na}^{+}$entry into or active $\mathrm{Na}^{+}$extrusion from the epithelial cells (4). Measurements that are likely to be related to the passive $\mathrm{Na}^{+}$permeability of paths through (amiloride-sensitive conductance ${ }^{2}$ and amiloride affinity for tissue receptors [Fig. 1]) and/or around epithelial cells (amiloride-insensitive $\mathrm{Na}^{+}$permeability [Table I]) appear to be similar in both subject populations. These findings indicate that any "excessive" $\mathrm{Na}^{+}$absorption across CF tissue is probably not a consequence of an increased density of $\mathrm{Na}^{+}$entry sites. Hence, an increased rate of active $\mathrm{Na}^{+}$transport would require in CF a greater driving force(s) for en- try, specifically, decreased cell $\mathrm{Na}^{+}$concentration and/or increased intracellular negativity.

$A$ raised $P D$ associated with increased active $\mathrm{Na}^{+}$ transport in CF airway epithelia could also cause a decrease in apical $\mathrm{Cl}^{-}$permeability. Voltage dependent $\mathrm{Cl}^{-}$permeability of electrically excitable membranes is well documented (13). Certain methods of depolarization of excised airway epithelia, e.g., raised submucosal $\mathrm{K}^{+}$concentration, increase transepithelial $\mathrm{Cl}^{-}$permeability (14). However, effects of hyperpolarization on $\mathrm{Cl}^{-}$permeability have not been reported.

Alternatively, the small $\mathrm{Cl}^{-}$permeability of the luminal border of the CF nasal epithelium raises the possibility that this defect alone could explain the abnormalities we observed. For example, we have noted a pattern of amiloride action on airway epithelia (1517). Despite the fact that $\mathrm{Na}^{+}$absorption accounted for $>75 \%$ of the basal short circuit current, the drug inhibited short circuit current or PD $\sim 50 \%$. This discrepancy does not reflect an amiloride-insensitive $\mathrm{Na}^{+}$ absorptive flow (because $\mathrm{Na}^{+}$absorption was abolished), but rather, the induction of $\mathrm{Cl}^{-}$secretion. A similar pattern of ion flow was induced by exposure to the luminal surface to $\mathrm{Na}^{+}$-free solution $(16,17)$. The proposed mechanism for this $\mathrm{Cl}^{-}$secretion is related to an increase in the electrical force that drives $\mathrm{Cl}^{-}$ passively across the luminal membrane and has been described elsewhere $(16,18)$. If $\mathrm{Cl}^{-}$permeability of the apical surface is lower in CF airway epithelia, then $\mathrm{Cl}^{-}$ secretion cannot be induced by amiloride and the PD (or short circuit current) in the presence or absence of drug would be related only to the rate of $\mathrm{Na}^{+}$absorption. The expected result is greater amiloride efficacy in CF tissue.

It is more difficult to explain the raised PD of CF airway epithelia with this model. On the assumption that $\mathrm{Cl}^{-}$permeation is the major determinant of apical (luminal) membrane PD of normal airway epithelia, a lower apical $\mathrm{Cl}^{-}$permeability in $\mathrm{CF}$ would shift determination of the PD to the ion species with the largest product of permeability and average transmembrane concentration. If this ion is $\mathrm{Na}^{+}$, then the lumen should become more negative. This hypothesis is supported by the inverse relationship between resting $\mathrm{PD}$ and transepithelial $\mathrm{Cl}^{-}$permeability of rabbit trachea (19) and canine bronchi (18). However, there are few, if any, maneuvers that unequivocally test this hypothesis. Removal of $\mathrm{Cl}^{-}$from the luminal solution induced the expected hyperpolarization of nasal (Table II) and other airway epithelia $(16,18)$ but $\mathrm{Cl}^{-}$ permeability was probably not affected, so that $\mathrm{Cl}^{-}$ gradients could still contribute to the PD. Indomethacin has been touted as an agent that selectively inhibits the $\mathrm{Cl}^{-}$permeability of apical membranes of the surface epithelium of excised canine trachea (20). Even though the canine trachea secretes $\mathrm{Cl}^{-}$by a 
mechanism that appears to be similar to that of fourth to sixth generation bronchi (18), indomethacin depolarizes the trachea (21) and hyperpolarizes large bronchi only slightly (unpublished).

Any explanation of an epithelial defect(s) in CF should be compatible with the composition of the liquid that fills or lines the epithelial lumen. Although evaluation of airway surface liquid composition may be complicated by chronic airway infection (3), the liquid in the lumens of airways $(22,23)$ and of other uninfected epithelial structures appears to be dehydrated (1). It is obvious that raised or "excessive" active $\mathrm{Na}^{+}$transport across the superficial epithelium that drives $\mathrm{Cl}^{-}$and water from the luminal surface of airways could result in dessication of the macromolecules left behind. Since the permeability of the cellular path to $\mathrm{Cl}^{-}$in $\mathrm{CF}$ is small, the transport force would have to be great enough to drive most of the counterion flow through the large paracellular paths. In contrast, if the abnormality in respiratory epithelia is reflected in a smaller $\mathrm{Cl}^{-}$permeability and the active $\mathrm{Na}^{+}$transport path is normal, then the control of airway surface liquid composition and volume is more complex. For example, Schulz (24) and Quinton (25) have suggested that an increased resistance to counterion movement (decreased $\mathrm{Cl}^{-}$permeability) retards hyperosmotic $\mathrm{Na}^{+}$absorption by the $\mathrm{CF}$ sweat duct epithelium, thereby increasing the $\mathrm{NaCl}$ in and osmolality of sweat. Consequently, sweat duct and airway epithelium may share a common defect in ion permeability. However, liquid on the bronchial surface is probably isosmotic (26), so that inhibition of $\mathrm{NaCl}$ absorption would be expected to retain volume on airway surfaces, a prediction that is not consistent with measurements of thicker, "dessicated" surface liquid in CF airways. On the other hand, reduced $\mathrm{Cl}^{-}$ permeability that results in decreased $\mathrm{Cl}^{-}$secretion in CF would remove a driving force that tends to add salt and water to the airway surface. Normal $\mathrm{Na}^{+}$ transport would continue to drive volume away from the surface. The result is raised net salt and water absorption by CF airways.

We have no evidence that the missing path of $\mathrm{Cl}^{-}$ permeation in CF contributes to dehydration of airway surface liquid, and the evidence that $\mathrm{Cl}^{-}$secretion by the superficial epithelium may play a role in the regulation of surface liquid of normal airways in vivo is limited. We "artifically" induced $\mathrm{Cl}^{-}$secretion in bronchi by treatment of the luminal surface with amiloride or by replacement of $\mathrm{Na}^{+}$in the luminal bathing solution. Indole compounds, such as serotonin, have been shown to exert an amiloride-like action on excised primate bronchi (27). Histochemical data suggest that similar compounds are contained in neu- roendocrine cells that lie beneath the airway epithelium. We do not know that these substances are released from the cells of storage nor can we predict that an effective concentration would accumulate near the site of action. Consequently, it is difficult to know whether these or other compounds affect $\mathrm{Na}^{+}$permeability in vivo by an amiloride-like mechanism that may also induce $\mathrm{Cl}^{-}$secretion.

Other endogenous substances affect $\mathrm{Cl}^{-}$secretion by airways more directly. $\beta$-adrenergic agents induce changes in bioelectric properties of surface cells (21), and induce $\mathrm{Cl}^{-}$secretion in canine trachea (28). $\beta$ adrenergic agonists also tend to induce the secretion of $\mathrm{Cl}^{-}$by canine (29) and human bronchi (15) but the magnitude of the response is relatively small (10\% increase). Accordingly, there is evidence that neurotransmitters, neurohumors, and autocoids can modulate $\mathrm{Cl}^{-}$secretion by airway surface epithelia but there are no direct studies that measure the magnitude of this modulation.

It is also possible that defects in the function of airway surface epithelial cells play a minor role in liquid balance and that dysfunction of glandular secretion in all regions and/or of the surface epithelia of small airways are responsible for the major derangement of airways surface liquid in CF. Cells in the latter region are thought to secrete liquid (30). This secretion may be a vestige of volume flow that is driven by $\mathrm{Cl}^{-}$transport across the pulmonary epithelium of the fetus. But, there is no direct evidence for the production of surface liquid by distal airways or its control. In contrast, the salt and water output of glands in large airways is modulated by cholinergic and, in some species, adrenergic neurotransmitters (31). Whereas the output of mucous glycoprotein onto airway surfaces appears to be normal in $\mathrm{CF}$ (32), secretion of $\mathrm{NaCl}$ and water by glands has not been examined. Secretion of liquid by the acinus of sweat glands, however, has been studied and is normal (24).

Finally, our finding of decreased airway $\mathrm{Cl}^{-}$permeability in CF does not affect the rationale for consideration of agents such as amiloride for treatment of the disease. Inhibition of $\mathrm{Na}^{+}$(and, presumably, $\mathrm{Cl}^{-}$ and water) absorption remains a possible therapeutic objective, even though the diseased epithelium may lack a potential compensatory process $\left(\mathrm{Cl}^{-}\right.$secretion). Consequently, optimal surface liquid volume and composition may be even more difficult to achieve than we had originally supposed.

\section{ACKNOWLEDGMENTS}

The authors wish to thank Ms. Lori Gatzy and Ms. D. Jones for expert technical assistance and Dr. M. J. Stutts and Dr. P. A. Bromberg for critical review of the manuscript. 
This work was supported by National Heart, Lung, and Blood Institutes grants HL00787, HL22924, and HL16674. Dr. Boucher is an Established Investigator of the American Heart Association.

\section{REFERENCES}

1. Dearborn, D. G. 1976. Water and electrolytes of exocrine secretions. In Cystic Fibrosis: Projections into the Future. J. A. Mangos and R. C. Talamo, editors. Symposia Specialists, New York. 179-191.

2. Davis, P. B., and P. A. Di Sant'Agnese. 1980. A review. Cystic fibrosis at forty-quo vadis? Pediatr. Res. 14: 8387.

3. Wood, R. E., T. F. Boat, and C. F. Doershuk. 1976. State of the art: cystic fibrosis. Am. Rev. Respir. Dis. 113: 833878.

4. Knowles, M. R., J. T. Gatzy, and R. C. Boucher. 1981 Increased bioelectric potential difference across respiratory epithelia in cystic fibrosis. N. Engl. J. Med. 305: 1489-1495.

5. Boucher, R. C. Jr., P. A. Bromberg, and J. T. Gatzy. 1980. Airway transepithelial electric potential in vivo: species and regional differences. J. Appl. Physiol. 48: 169-176.

6. Knowles, M. R., J. L. Carson, A. M. Collier, J. T. Gatzy, and R. C. Boucher. 1981. Measurements of nasal transepithelial electric potential differences in normal human subjects in vivo. Am. Rev. Respir. Dis. 124: 484-490.

7. Gatzy, J. T., L. Reuss, and A. L. Finn. 1979. Amphotericin $\mathrm{B}$ and $\mathrm{K}^{+}$transport across excised toad urinary bladder. Am. J. Physiol. 237: F145-F156.

8. Knowles, M. R., G. F. Murray, J. T. Gatzy, and R. C. Boucher. 1982. Effect of amiloride (Am) on ion transport across human bronchi in vitro. Am. Rev. Respir. Dis. 125: 242. (Abstr.)

9. Cuthbert, A. W. 1974. Characteristics of sodium channels in transporting epithelia. In Drugs and Transport Processes. B. A. Callingham, editor. University Press, Baltimore. 173-184.

10. Boucher, R. C. 1980 . Chemical modulation of airway epithelial permeability. Environ. Health Perspect. 35: $3-11,1980$.

11. Gatzy, J. T., and R. C. Boucher. 1982. Paths of hydrophilic solute flow across excised canine airways. Fed. Proc. 41: 1245. (Abstr.)

12. Gatzy, J. T., and T. W. Clarkson, 1965. The effect of mucosal and serosal solution cations on bioelectric properties of the isolated toad bladder. J. Gen. Physiol. 48: 647-671.

13. White, M. M., and C. Miller. 1981. Probes of the conduction process of a voltage-gated $\mathrm{Cl}^{-}$channel in Torpedo electroplax. J. Gen. Physiol. 78: 1-18.

14. Stutts, M., R. Boucher, and J. T. Gatzy. 1980. Effects of $\mathrm{KCl}$ on excised canine tracheal epithelium. Physiologist. 23: 62. (Abstr.)

15. Knowles, M. R., G. F. Murray, J. A. Shallal, J. T. Gatzy, and R. C. Boucher. 1982. Ion transport in excised human bronchi and its neurohumoral control. Chest. 81S: 11S$13 S$.

16. Boucher, R. C., and J. T. Gatzy. 1982. Characteristics of sodium transport by excised rabbit trachea. J. Appl. Physiol. In press.
17. Boucher, R. C., and J. T. Gatzy. 1981. Effect of amiloride (Am) and mucosal sodium removal on canine bronchial ion transport. Fed. Proc. 40: 447. (Abstr.)

18. Boucher, R. C., J. Narvarte, C. Cotton, M. J. Stutts, M. R. Knowles, A. L. Finn, and J. T. Gatzy. 1982. Sodium absorption in mammalian airways. In Fluid and Electrolyte Abnormalities in Exocrine Glands in Cystic Fibrosis. P. M. Quinton, J. R. Martinez, and U. Hopfer, editors. San Francisco Press, Inc., San Francisco. 271288.

19. Jarnigan, F., J. D. Davis, P. A. Bromberg, J. T. Gatzy, and R. C. Boucher. 1982. Bioelectric properties and ion transport across excised rabbit trachea. J. Appl. Physiol. In press.

20. Al-Bazzaz, F. J., V. P. Yadava, and C. Westenfelder. 1981. Modifications of $\mathrm{Na}$ and $\mathrm{Cl}$ transport in canine tracheal mucosa by prostaglandins. Am. J. Physiol. 240: F101-105.

21. Frizzell, R., M. Welsh, and P. Smith. 1981. Hormonal control of chloride secretion by canine tracheal epithelium: An electrophysiologic analysis. Ann. NY Acad. Sci. 372: 558 .

22. Chernick, W. S., and G. J. Barbero. 1959. Composition of tracheobronchial secretions in cystic fibrosis of the pancreas and bronchiectasis. Pediatrics. 24: 739-745.

23. Potter, J. L., L. W. Matthews, S. Spector, and J. Lemm. 1967. Studies on pulmonary secretions. II. Osmolality and the ionic environment of pulmonary secretions from patients with cystic fibrosis, bronchiectasis, and laryngectomy. Am. Rev. Respir. Dis. 96: 83-87.

24. Schulz, I. J. 1969. Micropuncture studies of the sweat formation in cystic fibrosis patients. J. Clin. Invest. 48: 1470-1477.

25. Quinton, P. M. 1982. Abnormalities in electrolyte secretion in cystic fibrosis sweat glands due to decreased anion permeability. In Fluid and Electrolyte Abnormalities in Exocrine Glands in Cystic Fibrosis. P. M. Quinton, J. R. Martinez, and U. Hopfer, editors. San Francisco Press, Inc., San Francisco. 53-76.

26. Boucher, R. C., M. J. Stutts, P. A. Bromberg, and J. T Gatzy. 1981. Regional differences in airway surface liquid composition. J. Appl. Physiol. 50: 613-620.

27. Legris, G., P. Will, and U. Hopfer. 1981. Effects of serotonin on ion transport in intestinal and respiratory epithelium. Ann. NY Acad. Sci. 372: 345-346.

28. Al-Bazzaz, F. J., and E. Cheng. 1979. Effect of catecholamines on ion transport in dog tracheal epithelium. J. Appl. Physiol.: Respir. Environ. Exercise Physiol. 47: 397-403.

29. Boucher, R. C., and J. T. Gatzy. 1982. Regional effects of autonomic agents on ion transport across excised canine airways. J. Appl. Physiol.: Respir. Environ. Exercise Physiol. 52(4): 893-901.

30. Kilburn, K. H. 1968. A hypothesis for pulmonary clearance and its implications. Am. Rev. Respir. Dis. 98: 449463.

31. Nadel, J. A., B. Davis, and R. J. Phipps. 1979. Control of mucus secretion and ion transport in airways. Ann. Rev. Physiol. 41: 369-382.

32. Boat, T. F., and P. W. Cheng. 1976. Glycoproteins. In Cystic Fibrosis: Projections into the Future. J. A. Mangos and R. C. Talamo, editors. Grune and Stratton, Inc., New York. 165-179. 